\title{
Height differences and the associations between food insecurity, percentage body fat and BMl among men and women
}

\author{
Francis A Tayie ${ }^{1, *}$ and Claire A Zizza ${ }^{2}$ \\ 'Department of Human Environmental Studies, 1150 S. Washington Street, 205 Wightman Hall, Central \\ Michigan University, Mount Pleasant, MI 48859, USA: ${ }^{2}$ Department of Nutrition and Food Science, Auburn \\ University, Auburn, AL 36849, USA
}

Submitted 11 May 2008: Accepted 7 December 2008: First published online 23 February 2009

\begin{abstract}
Objective: The present study examined the associations between adult food insecurity (FI) and percentage body fat (\%BF) and BMI, stratified by height (HT). Design, setting and subjects: \%BF, HT and BMI of 2117 men and 1909 women in the National Health and Nutrition Examination Survey 1999-2002 were analysed in relation to adult food security status using multiple regression procedures. Results: Compared with the fully food-secure, men's \%BF, BMI and HT were lower as FI intensified. Marginal food security among women was associated with $1 \cdot 3 \mathrm{~cm}$ shorter HT, $P=0 \cdot 016$. Marginal food security among women who were below median HT was associated with about $2 \cdot 0 \mathrm{~kg} / \mathrm{m}^{2}$ higher BMI, $P=0 \cdot 042$. $\% \mathrm{BF}$ was not associated with FI among women.

Conclusions: FI is associated with shorter HT and lower \%BF and BMI in men. Women's HT should be considered in the reported associations between FI and higher BMI.
\end{abstract}

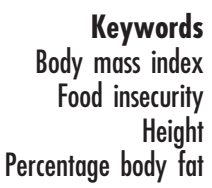

Between 1995 and 2006, the prevalence of adult food insecurity (FI), defined as having limited or uncertain availability of nutritionally adequate and safe foods or limited or uncertain ability to acquire acceptable foods in socially acceptable ways ${ }^{(1)}$, fluctuated between $9 \cdot 5$ and $11.9 \%{ }^{(2)}$ in the USA. Several research reports indicate that food-insecure individuals are at higher risk of overweight and obesity (OWOB) and obesity-related health problems ${ }^{(3,4)}$. Intermediate levels of FI are associated with higher BMI in women ${ }^{(5-7)}$ and in some cases men ${ }^{(5,8)}$. These associations have been observed to vary by the level and severity of $\mathrm{FI}^{(9)}$. The mechanisms responsible for the positive association between FI and BMI in women have not been established but several plausible explanations have been offered, including socio-economic deprivation, adaptive coping behaviour and lack of access to resources $^{(7,10-12)}$. However, these are characteristics indicative of low socio-economic status, which is associated with shorter height $(\mathrm{HT})^{(13-15)}$

To our knowledge, nutritional indicators that reflect earlier life experiences, such as HT, have not been documented among food-insecure adults living in the USA. Short HT arising from inadequate nutrition has been observed in developing countries for several dec$\operatorname{ades}^{(14,16)}$. Long-term nutritional deficiencies among vulnerable populations such as the food-insecure engender HT deficits in adults ${ }^{(13,16)}$. Inadequate nutrition can result in inadequate intakes of nutrients essential for linear growth, including iodine, $\mathrm{Zn}$, Ca, vitamin $\mathrm{A}$, protein and energy, one consequence of which is HT deficits in adults $^{(16,17)}$. Studies show that people who experience undernutrition at a young age recover in weight but not in $\mathrm{HT}^{(13,18,19)}$.

Bioelectrical impedance analysis (BIA) is one method used for the assessment of percentage body fat $(\% \mathrm{BF})^{(20-22)}$. Whereas researchers have examined the associations between FI and OWOB using BMI, to our knowledge none have examined the associations using $\% \mathrm{BF}$ derived from BIA. If a positive association exists between FI and BMI among women, a positive association between $\mathrm{FI}$ and \% $\mathrm{BF}$ in women would be expected. The purpose of the present study was to examine the associations between FI and \% BF and BMI, and whether these associations vary by HT.

\section{Methods}

\section{Study sample and data sources}

Cross-sectional data from the National Health and Nutrition Examination Survey (NHANES) 1999-2002 were used for the present study. The NHANES is a nationally representative survey conducted by the National Center for Health Statistics (NCHS) of the Centers for Disease 
Control and Prevention. Stratified, multistage probability cluster sampling methods were used in the NHANES. It is an ongoing survey that covers the non-institutionalized US civilian population.

Because prior researchers have reported associations between FI and OWOB in adults, those 18-50 years of age were selected for the present analysis. In addition, this age range was selected because body composition and HT vary markedly in younger and older persons ${ }^{(23,24)}$ and the use of BMI to assess adiposity in older adults has been questioned ${ }^{(25,26)}$.

From the baseline sample of 4048 who had complete BIA and food security data in the NHANES 1999-2002, a total of 4026 (99.46\%) subjects comprising 2117 men and 1909 women were included after meeting various inclusion criteria, i.e. has complete data on age, body weight, food security status, gender and HT, and not having extremely low or extremely high \%BF. Twenty-two subjects, comprising $0.54 \%$ of the baseline sample, did not satisfy the inclusion criteria and thus were excluded from analysis. Of the twenty-two subjects who did not meet the inclusion criteria, two subjects had missing data for body weight. Six and fourteen had extremely low and high \%BF respectively, were clear outliers and thus were excluded from the study. The NCHS Ethics Review Board approved the survey protocols and informed consent was obtained from all subjects. The procedures for the present study were approved locally by the Institutional Review Board, Office of Human Subjects Research, Auburn University, Alabama.

\section{Food security measure}

In the NHANES 1999-2002, depending on the number of affirmative answers to a subset of ten items pertaining to adults from the core eighteen-item US food security survey module, subjects were assigned to one of four food security levels: (i) fully food-secure; (ii) marginal food security (affirmative answers to one or two of the questions about food security, suggesting a risk for FI); (iii) food-insecure without hunger (reported uncertainty about food supply, a need to adapt food management strategies or indicative of a decrease in diet quality); or (iv) food-insecure with hunger (both quality and quantity of food decreased to the extent that there was repeated experience of the physical sensations of hunger) ${ }^{(2,8)}$. Food security questions asked during the survey referred to food-related circumstances in the past 12 months prior to administration of the food security questionnaire ${ }^{(2)}$.

\section{Body fat and beight assessment}

A bioimpedance spectrum analyser (HYDRA ECF/ICF 4200; Xitron Technologies, Inc., San Diego, CA, USA) was used for BIA, which involved tetrapolar measurement of whole-body electrical resistance. In the NHANES 1999-2002, BIA examinations were conducted by trained health technicians in the mobile examination centres $(\mathrm{MEC})^{(27)}$. In the present study, BIA values at $50 \mathrm{kHz}$ electrical current were used to estimate fat-free body mass (FFM) by utilizing a prediction equation for adult men and women which has been validated against dualenergy X-ray absorptiometry ${ }^{(22)}$. Utilizing this equation $^{(22)}$, fat-free mass was estimated as:

$$
\begin{aligned}
\text { FFM }= & -4.104+\left(0.518 \times \mathrm{H}^{2} / \mathrm{R}\right)+(0 \cdot 231 \times \text { weight }) \\
& +(0 \cdot 130 \times \text { reactance })+(4 \cdot 229 \times \text { gender; males } \\
& =1, \text { females }=0)
\end{aligned}
$$

where $H^{2} / R$ is HT squared divided by resistance $\left(\mathrm{cm}^{2} / \Omega\right)$. From the estimated FFM, the \%BF was calculated as follows $^{(28)}$ :

$\% \mathrm{BF}=[($ body weight $-\mathrm{FFM}) \div$ body weight $] \times 100$.

$\% \mathrm{BF}$ values were calculated separately for men and women. Subjects who were measured in the BIA sample in the NHANES 1999-2002 were within the ages 18-50 years.

In the NHANES 1999-2002, HT was measured by trained technicians using a stadiometer equipped with an integrated survey information system ${ }^{(29)}$. Further details on HT and other anthropometric measurements are available elsewhere ${ }^{(29)}$.

\section{Statistical analysis and covariates}

To correct for MEC sampling design and to apply MEC sampling weights ${ }^{(30)}$, the STATA statistical software package version $10 \cdot 0$ (StataCorp., College Station, TX, USA) was used to estimate all descriptive and inferential statistics. Due to reported differences in the association between FI and body weight status between men and women, all analyses were stratified by gender ${ }^{(5,10)}$.

For categorical data, Pearson's $\chi^{2}$ test of independence with Rao and Scott correction was used, whereas for continuous variables, the overall $F$ test was used to test for significant bivariate associations across levels of food security $^{(31,32)}$.

Multiple linear regression models were used to examine the associations between FI and \%BF, BMI and HT. In multiple linear regression models, second-order interaction terms of FI and HT were tested (Wald $F$ test) to determine if HT modified the association between FI and BMI. Because the interaction terms were significant, we stratified the FI models for \%BF and BMI by HT. We stratified subjects into those below median HT and median HT or taller as follows for this sample: (i) for men, below median HT was $<174.7 \mathrm{~cm}$ and median HT or taller was $\geq 174.7 \mathrm{~cm}$; and (ii) for women, below median HT was $<161.7 \mathrm{~cm}$ and median HT or taller was $\geq 161 \cdot 7 \mathrm{~cm}$.

Covariates included in all multiple linear regression models were age, education, ethnicity/race, income and smoking status because of reported associations with body weight ${ }^{(13,33,34)}$. Age, \%BF, BMI, HT and income were examined as continuous variables whereas education, ethnicity and smoking status were examined as indicator variables. Level of education was classified as less than high school degree and high school degree or 
higher. Due to small sample sizes, race/ethnicity was collapsed into three categories: Black non-Hispanic; Mexican-American and other Hispanics; and White non-Hispanic plus others. In the NHANES 1999-2002, respondents who reported they currently smoked at least 100 cigarettes, a pipe twenty times and a cigar twenty times in their lifetime were classified as current smokers. Others who reported previous smoking were classified as ex-smokers. Those who reported never smoking to all were classified as never smokers.

In testing for associations between the main exposure variable (food security status) and the outcome variables (\%BF, BMI and HT), the fully food-secure category was the referent group and did not include the marginal food security category. The significance of the independent association of FI was assessed by means of a $t$ test on the $\beta$ coefficients. In all statistical tests, significant differences were tested at $P<0 \cdot 05$.

\section{Results}

\section{Sample characteristics}

Background characteristics of the subjects are presented in Table 1 . Of the 4026 subjects in the study, 52\% were men and $48 \%$ were women. Subjects who were fully food-secure made up $82 \cdot 01 \%$ of this sample. The mean BMI of the subjects was $26 \cdot 76(\mathrm{se} 0 \cdot 10) \mathrm{kg} / \mathrm{m}^{2}$ for men and $27 \cdot 41($ se $0 \cdot 24) \mathrm{kg} / \mathrm{m}^{2}$ for women. The other characteristics of the subjects across the four levels of food security are shown in Table 1.

\section{Percentage body fat, BMI and beight}

There was significant interaction between food security status and HT in the association between FI and BMI as indicated by the adjusted Wald test, $P<0 \cdot 038$. This result indicates that the trends in the association between FI and BMI were different at different levels of HT.

Table 2 shows the \%BF of men and women by food security status. Men who were food-insecure without hunger or with hunger had significantly lower \%BF than men who were fully food-secure. This pattern did not change after HT stratification in men (Table 3). Compared with fully food-secure women, FI was not significantly associated with \%BF among women, not even after HT stratification (Table 3).

Men who were food-insecure without hunger or with hunger had significantly lower BMI than men who were fully food-secure (Table 2), irrespective of HT (Table 3). Different patterns of association were observed among women. Before HT stratification, there was only a marginally significant positive association between FI and BMI (Table 2) among women. However, after HT stratification, women who were marginally food-secure and were below median HT had an approximately $2 \mathrm{~kg} / \mathrm{m}^{2}$ higher BMI compared with their fully food-secure counterparts, $P=0 \cdot 042$ (Table 3). Compared with their fully food-secure counterparts, no significant differences in BMI were observed among women who were of median HT or taller.

Men who experienced FI without and with hunger had significantly shorter HT by about $2 \mathrm{~cm}$ compared with fully food-secure men. Among women, marginal food security was associated with approximately $1.3 \mathrm{~cm}$ shorter HT, $P=0 \cdot 016$. Although insignificant, there was a tendency for women in the other food-insecure categories to be shorter than their fully food-secure counterparts.

\section{Discussion}

A significant finding in the present study is that women who were marginally food-secure and were below median HT had significantly higher BMI, but women who were of median HT or taller did not. Although not statistically significant, BMI showed a tendency towards higher values among food-insecure women who were below median HT. Among women, no association was found between FI and \% BF which is a more sensitive measure of adiposity. Our results indicate that, unlike $\mathrm{BMI}$ \%BF did not vary by HT among women. The importance of HT in FI and BMI analysis was observed earlier and included as a control variable in a study which reported a moderate $(P=0.06)$ but positive association between FI and $\mathrm{BMI}^{(11)}$. Our results suggest that HT should be considered when examining the association between FI and BMI.

We observed that marginal food security was associated with shorter HT in women. In the case of men, it was the extreme forms of FI, food-insecure without and with hunger, which were significantly associated with shorter HT. The observation that FI was associated with shorter HT among men and women was not unexpected because HT deficits result from chronic undernutrition $^{(14,16)}$, which is a possible consequence of FI. It was difficult to glean from available data whether women who were below median HT in the present study had experienced FI for a longer duration than those who were of median HT or taller. However, an earlier report indicated that about two-thirds of food-insecure persons in the USA experience FI as recurring while one-fifth experience it as frequent or chronic ${ }^{(35)}$.

Low-income individuals, who largely include those who are food insecure, are associated with shorter $\mathrm{HT}^{(13,15)}$, probably due to difficulties in obtaining optimum nutrition during their growing years ${ }^{(14,16,36)}$. Ensuring adequate nutrition by alleviating FI would improve adult HT and perhaps help to ameliorate its influence on the development and progression of obesity. Improvement in adult HT is exigent because several disease risks have been associated with short HT in adults. Short adult HT is associated with risk of CHD and stroke mortality ${ }^{(31,37)}$. 


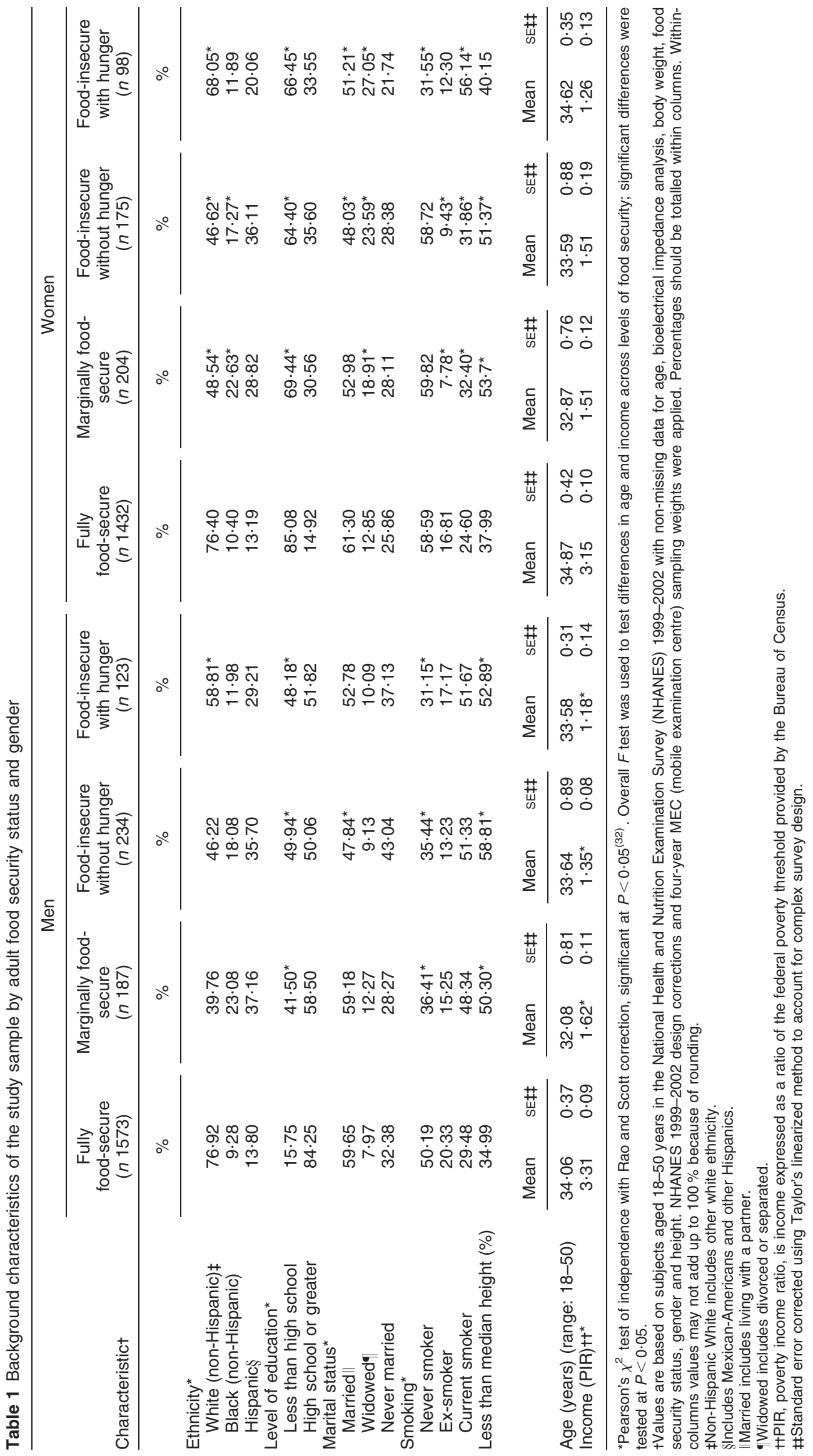


Table 2 Anthropometric characteristics of the study sample categorized by gender and adult food security status

\begin{tabular}{|c|c|c|c|c|c|c|c|c|}
\hline \multirow[b]{3}{*}{ Measure } & \multicolumn{8}{|c|}{ Food security statust } \\
\hline & \multicolumn{2}{|c|}{ Fully food-secureł } & \multicolumn{2}{|c|}{ Marginal food security } & \multicolumn{2}{|c|}{ Food-insecure without hunger } & \multicolumn{2}{|c|}{ Food-insecure with hunger } \\
\hline & Mean & $\mathrm{SE} \S$ & Mean & $\mathrm{SE} \S$ & Mean & $\mathrm{SE} \S$ & Mean & $\mathrm{SE} \S$ \\
\hline Men & \multicolumn{2}{|c|}{$(n$ 1573) } & \multicolumn{2}{|c|}{$(n$ 187) } & \multicolumn{2}{|c|}{ (n 234) } & \multicolumn{2}{|c|}{$(n$ 123) } \\
\hline Weight (kg)\| & $84 \cdot 78$ & $0 \cdot 28$ & $82 \cdot 53$ & $1 \cdot 26$ & $76 \cdot 33^{*}$ & $1 \cdot 71$ & $75 \cdot 47^{\star}$ & $1 \cdot 42$ \\
\hline Percentage body fat\| & $24 \cdot 91$ & $0 \cdot 18$ & $26 \cdot 01$ & $0 \cdot 70$ & $22 \cdot 82^{*}$ & 0.92 & $22 \cdot 23^{*}$ & 0.75 \\
\hline BMI $\left(\mathrm{kg} / \mathrm{m}^{2}\right) \|$ & $26 \cdot 98$ & $0 \cdot 21$ & $27 \cdot 43$ & $0 \cdot 72$ & $25 \cdot 51^{*}$ & $0 \cdot 74$ & $25 \cdot 55^{\star}$ & 0.66 \\
\hline Height (cm) $\|$ & $177 \cdot 08$ & $0 \cdot 27$ & $176 \cdot 46$ & 0.73 & $175 \cdot 05^{\star}$ & 0.94 & $175 \cdot 25^{\star}$ & 0.93 \\
\hline Women & \multicolumn{2}{|c|}{$(n$ 1432) } & \multicolumn{2}{|c|}{$(n$ 204) } & \multicolumn{2}{|c|}{$(n$ 175) } & \multicolumn{2}{|c|}{$(n 98)$} \\
\hline Weight (kg) & $72 \cdot 75$ & 0.69 & $74 \cdot 84$ & $1 \cdot 38$ & $72 \cdot 72$ & $2 \cdot 19$ & $73 \cdot 81$ & $2 \cdot 40$ \\
\hline Percentage body fat\| & 35.94 & 0.27 & $35 \cdot 66$ & 0.63 & $35 \cdot 66$ & 0.93 & $35 \cdot 00$ & $1 \cdot 03$ \\
\hline BMI $\left(\mathrm{kg} / \mathrm{m}^{2}\right) \|$ & $27 \cdot 24$ & $0 \cdot 22$ & $28 \cdot 13$ & 0.58 & $27 \cdot 23$ & $0 \cdot 78$ & $26 \cdot 94$ & 0.98 \\
\hline Height (cm) $\|$ & $163 \cdot 54$ & $0 \cdot 15$ & $162 \cdot 26^{*}$ & 0.50 & $163 \cdot 00$ & 0.59 & $163 \cdot 66$ & 0.76 \\
\hline
\end{tabular}

*Significantly different from the fully food-secure category, $P<0 \cdot 05$. The $t$ statistic on each $\beta$ coefficient was used to determine significance.

tValues are based on subjects aged 18-50 years in the National Health and Nutrition Examination Survey (NHANES) 1999-2002 with non-missing data for age, bioelectrical impedance analysis, body weight, food security status, gender and height. NHANES 1999-2002 design corrections were applied and all estimates were weighted using NHANES four-year MEC (mobile examination centre) sampling weights.

‡Food-secure men and women were the referent groups.

§Standard error corrected using Taylor's linearized method to account for complex survey design.

॥Values were adjusted using gender-stratified multiple regression models which controlled for age, education, ethnicity, income and smoking.

Table 3 Percentage body fat (\%BF) and BMI categorized by adult food security status and height (HT)

\begin{tabular}{|c|c|c|c|c|c|c|c|c|}
\hline \multirow[b]{3}{*}{ Measuret } & \multicolumn{8}{|c|}{ Food security status $\neq$} \\
\hline & \multicolumn{2}{|c|}{ Fully food-secure } & \multicolumn{2}{|c|}{ Marginal food security } & \multicolumn{2}{|c|}{ Food-insecure without hunger } & \multicolumn{2}{|c|}{ Food-insecure with hunger } \\
\hline & Mean & SEll & Mean & SE $\|$ & Mean & SE $\|$ & Mean & SE\| \\
\hline \multicolumn{9}{|l|}{ Men } \\
\hline Below median $\mathrm{HT}(<174.7 \mathrm{~cm})$ & \multicolumn{2}{|c|}{$(n 669)$} & \multicolumn{2}{|c|}{$(n 108)$} & \multicolumn{2}{|c|}{$(n 155)$} & \multicolumn{2}{|c|}{$(n 79)$} \\
\hline$\% B F$ & $23 \cdot 78$ & $0 \cdot 26$ & $24 \cdot 36$ & 1.07 & $21 \cdot 60^{*}$ & $1 \cdot 18$ & $21 \cdot 57^{*}$ & $1 \cdot 22$ \\
\hline BMI $\left(\mathrm{kg} / \mathrm{m}^{2}\right)$ & 26.98 & $0 \cdot 21$ & $27 \cdot 43$ & $0 \cdot 72$ & $25 \cdot 51^{*}$ & 0.74 & $25 \cdot 55^{\star}$ & 0.66 \\
\hline Median HT or taller $(\geq 174.7 \mathrm{~cm})$ & \multicolumn{2}{|c|}{$(n 904)$} & \multicolumn{2}{|c|}{$(n 79)$} & \multicolumn{2}{|c|}{$(n 79)$} & \multicolumn{2}{|c|}{$(n$ 44) } \\
\hline$\% \mathrm{BF}$ & $25 \cdot 53$ & 0.20 & $26 \cdot 92$ & $1 \cdot 20$ & $23 \cdot 55^{\star}$ & $1 \cdot 24$ & $22 \cdot 01^{*}$ & $1 \cdot 23$ \\
\hline BMI $\left(\mathrm{kg} / \mathrm{m}^{2}\right)$ & $27 \cdot 18$ & $0 \cdot 13$ & $27 \cdot 53$ & 0.72 & $25 \cdot 83^{*}$ & 0.69 & $24 \cdot 08^{*}$ & 0.93 \\
\hline \multicolumn{9}{|l|}{ Women } \\
\hline Below median HT $(<161 \cdot 7 \mathrm{~cm})$ & \multicolumn{2}{|c|}{$(n 646)$} & \multicolumn{2}{|c|}{$(n 117)$} & \multicolumn{2}{|c|}{$(n$ 109) } & \multicolumn{2}{|c|}{$(n 47)$} \\
\hline \%BF & $35 \cdot 76$ & $0 \cdot 43$ & $35 \cdot 95$ & 0.95 & $36 \cdot 15$ & $1 \cdot 05$ & 33.94 & $1 \cdot 60$ \\
\hline BMI $\left(\mathrm{kg} / \mathrm{m}^{2}\right)$ & $27 \cdot 72$ & 0.36 & $29 \cdot 60^{*}$ & 0.97 & 28.03 & 0.93 & $28 \cdot 59$ & $1 \cdot 56$ \\
\hline Median HT or taller $(\geq 161.7 \mathrm{~cm})$ & \multicolumn{2}{|c|}{$(n 786)$} & \multicolumn{2}{|c|}{$(n$ 87) } & \multicolumn{2}{|c|}{$(n 66)$} & \multicolumn{2}{|c|}{$(n 51)$} \\
\hline$\% \mathrm{BF}$ & $36 \cdot 06$ & $0 \cdot 29$ & $35 \cdot 33$ & 0.98 & $35 \cdot 16$ & $1 \cdot 52$ & $35 \cdot 36$ & $1 \cdot 00$ \\
\hline BMI $\left(\mathrm{kg} / \mathrm{m}^{2}\right)$ & 26.97 & $0 \cdot 26$ & $26 \cdot 69$ & $0 \cdot 84$ & $26 \cdot 70$ & $1 \cdot 40$ & $25 \cdot 73$ & 0.96 \\
\hline
\end{tabular}

*Significantly different from the fully food-secure category, $P<0.05$. The $t$ statistic on each $\beta$ coefficient was used to determine significance.

tMean values were adjusted using gender-stratified multiple regression models which controlled for age, education, ethnicity, income and smoking. National Health and Nutrition Examination Survey (NHANES) 1999-2002 design corrections were applied and all estimates were weighted using NHANES four-year MEC (mobile examination centre) sampling weights.

¥Values are based on subjects aged 18-50 years in the NHANES 1999-2002 with non-missing data for age, bioelectrical impedance analysis, BIA, body weight, food security status, gender and height.

$\S$ Food-secure men and women were the referent group.

IIStandard error corrected using Taylor's linearized method.

All-cause mortality risk was double for men who were below $165 \mathrm{~cm}$ in HT compared with taller men ${ }^{(38)}$. A significant association between short HT and higher incidence of prostate cancer has been reported ${ }^{(39)}$. Previous studies have shown food-insecure individuals to be at greater risk of developing many of these chronic diseases $^{(4,40,41)}$. Our finding that FI was associated with lower HT underscores the public health importance of nutrition programmes that target individuals during the critical times of growth. The positive influence on infant length and well-being through participation in federal food assistance programmes has been reported ${ }^{(42,43)}$.
$\% \mathrm{BF}$ and $\mathrm{BMI}$ showed similar trends across food security levels in men but not in women. Physiological adaptation in women such as leptin-mediated maintenance of critical fat mass for reproduction may contribute to obscure differences in \%BF across food security levels ${ }^{(44)}$. The levels of FI observed in this population may not indicate energy shortage among women ${ }^{(45)}$. In addition, differences in \% $\mathrm{BF}$ among women might have been obscured by the already elevated \%BF of the referent group, fully foodsecure women, in the present study.

The strengths of our study lie in the fact that we assessed two indicators of adiposity, \%BF and BMI, to 
study their associations with FI. Another strength is that the study accounted for important covariates including smoking status, which is common among food-insecure persons and influences their dietary intake and composition ${ }^{(46,47)}$ and body weight ${ }^{(48,49)}$. Available literature indicates that, unlike the present study, only a few controlled for smoking in the study of the associations between FI and $\mathrm{BMI}^{(50)}$. However, there is significant inverse association between smoking and body weight ${ }^{(49)}$. In the present study, food security status information covered a reference period of 12 months to improve sensitivity and to provide a more reliable assessment. Another important strength is that the study comprised a large sample of persons in the USA and that the conduct of the study was carefully standardized.

In the present study, we observed a significant interaction between food security status and HT in the association between FI and BMI. This observation indicates that the trend in the association between FI and BMI was different at different levels of HT. This observation further underscores the fact that HT should be considered when examining the association between FI and BMI as an index of obesity.

A limitation of the study is that the relationships between FI and \%BF and BMI were based on cross-sectional data which do not permit inferences related to causality ${ }^{(5,11)}$. BIA is a well-recognized method for $\% \mathrm{BF}$ assessment ${ }^{(20-22)}$. However, assessment of \%BF using BIA may not be appropriate for individuals who have extremely low or extremely high BMI because \%BF does not increase linearly with increasing body weight ${ }^{(51,52)}$. Even though our sample size is large, it must be noted that the present study is based on a subsample of the subjects in the larger NHANES 1999-2002. Thus the finding of the study may not be representative of the larger NHANES sample.

The present study shows that FI is associated with lower \%BF, BMI and HT in men, and marginal food security is associated with shorter HT in women. A significantly positive association of BMI with marginal food security was found among women who were below the median HT. These observations highlight the need for more vigorous public health efforts to alleviate the effects of FI and to improve food security in this population. Longitudinal studies, which should include repeated measures of FI, HT, weight and adiposity indicators across the life cycle, are needed to further elucidate the associations between FI and \%BF, BMI and HT.

\section{Acknowledgements}

The authors gratefully acknowledge the Alabama Agricultural Experiment Station for partially funding this study (ALA013-020). The authors have no conflict of interests. F.A.T. contributed to the general preparation of the manuscript including data gathering, cleaning, analysis and reporting, and the introduction, methods and dis- cussion sections. C.A.Z. conceptualized the objectives of the manuscript and made contributions in the introduction, methods, data analysis and discussion sections. We acknowledge the helpful technical inputs of Patricia Duffy during the preparation of this manuscript and thank Jocelyn Jacoby and Beibei Xu for their helpful comments during the preparation of the manuscript. All have given their consent to be acknowledged.

\section{References}

1. Life Science Research Office (LSRO) Expert Panel (2006) The Federation of American Societies for Experimental Biology, 1989. In Food Insecurity and Hunger in the United States: An Assessment of the Measure. Washington, DC: National Research Council.

2. Nord M, Andrews M \& Carlson S (2007) Household Food Security in the United States, 2006. Economic Research Report no. ERR-49. Washington, DC: US Department of Agriculture, Food Assistance \& Nutrition Research Program; available at http://www.ers.usda.gov/Publications/ERR49

3. Holben DH (2004) Food insecurity in the United States: its effect on our patients. Am Fam Physician 69, 1058-1063.

4. Vozoris NT \& Tarasuk VS (2003) Household food insufficiency is associated with poorer health. J Nutr 133, 120-126.

5. Wilde PE \& Peterman JN (2006) Individual weight change is associated with household food security status. $J$ Nutr 136, 1395-1400.

6. Adams EJ, Grummer-Strawn L \& Chavez G (2003) Food insecurity is associated with higher risk of obesity in California women. J Nutr 133, 1070-1074.

7. Dietz WH (1997) Periods of risk in childhood for the development of adult obesity: what do we need to learn? J Nutr 127, Suppl., 1884S-1886S.

8. Hanson KL, Sobal J \& Frongillo EA (2007) Gender and marital status clarify associations between food insecurity and body weight. J Nutr 137, 1460-1465.

9. Frongillo EA, Olson CM, Rauschenbach BA \& Kendall A (1997) Nutritional Consequences of Food Insecurity in a Rural New York State County. Discussion Paper no. 1120-97. Madison, WI: Institute for Research on Poverty, University of Wisconsin.

10. Sarlio-Lahteenkorva S \& Lahelma E (2001) Food insecurity is associated with past and present economic disadvantage and body mass index. J Nutr 131, 2880-2884.

11. Olson C (1999) Nutrition and health outcomes associated with food insecurity and hunger. J Nutr 129, Suppl., 521S-524S

12. Robertson AR, Brunner E \& Shilham A (1999) Food is a political issue. In Social Determinants of Health, pp. 179-210 [MWR Marmot, editor]. Oxford: Oxford University Press.

13. Kaluski DN, Keinan-Boker L, Stern F, Green MS, Leventhal A, Goldsmith R, Chinich A \& Berry EM (2007) BMI may overestimate the prevalence of obesity among women of lower socioeconomic status. Obesity (Silver Spring) 15, $1808-1815$.

14. Hakeem R (2001) Socio-economic differences in height and body mass index of children and adults living in urban areas of Karachi, Pakistan. Eur J Clin Nutr 55, 400-406.

15. Cavelaars AEJM, Kunst AE, Geurts JJM et al. (2000) Persistent variations in average height between countries and between socio-economic groups: an overview of ten European countries. Ann Hum Biol 27, 407-421.

16. Scrimshaw NS (2003) Historical concepts of interactions, synergism and antagonism between nutrition and infection. J Nutr 133, Suppl., 316S-321S. 
17. Giovannucci E, Rimm EB, Stampfer MJ, Colditz GA \& Willett WC (1997) Height, body weight, and risk of prostate cancer. Cancer Epidemiol Biomarkers Prev 6, 557-563.

18. Benefice E, Garnier D, Simondon KB \& Malina RM (2001) Relationship between stunting in infancy and growth and fat distribution during adolescence in Senegalese girls. Eur J Clin Nutr 55, 50-58.

19. Dulloo AG \& Girardier L (1993) Adaptive role of energy expenditure in modulating body fat and protein deposition catch-up growth after early undernutrition. Am J Clin Nutr 58, 614-621.

20. Frisard MI, Greenway FL \& DeLany JP (2005) Comparison of methods to assess body composition changes during a period of weight loss. Obes Res 13, 845-854.

21. Bolanowski M \& Nilsson BE (2001) Assessment of human body composition using dual-energy X-ray absorptiometry and bioelectrical impedance analysis. Med Sci Monit 7, 1029-1033.

22. Kyle U, Genton L, Karsegard L, Slosman D \& Pichard C (2001) Single prediction equation for bioelectrical impedance analysis in adults aged 20-94 y. Nutrition 17, 248-253.

23. Newman AB, Yanez D, Harris T, Duxbury A, Enright PL \& Fried LP (2001) Weight change in old age and its association with mortality. J Am Geriatr Soc 49, 1309-1318.

24. Snead DB, Birge SJ \& Kohrt WM (1993) Age-related differences in body composition by hydrodensitometry and dual-energy X-ray absorptiometry. J Appl Physiol 74, 771-775.

25. Huffman GB (2002) Evaluating and treating unintentional weight loss in the elderly. Am Fam Physician 65, 640-650.

26. Omran ML \& Morley JE (2000) Assessment of protein energy malnutrition in older persons, Part II: laboratory evaluation. Nutrition 16, 131-140.

27. Centers for Disease Control and Prevention (2007) National Health and Nutrition Examination Survey. Body Composition Procedures Manual. Hyattsville, MD: US Department of Health and Human Services, CDC; available at http://www.cdc.gov/nchs/data/nhanes/bc.pdf

28. Zhu S, Wang Z, Shen S, Heymsfield SB \& Heshka S (2003) Percentage body fat ranges associated with metabolic syndrome risk: results based on the third National Health and Nutrition Examination Survey (1988-1994). Am J Clin Nutr 78, 228-235.

29. Centers for Disease Control and Prevention (2007) National Health and Nutrition Examination Survey. Anthropometric Procedures Manual. Hyattsville, MD: US Department of Health and Human Services, CDC; available at http://www.cdc.gov/nchs/data/nhanes/bm.pdf

30. Centers for Disease Control and Prevention (2005) National Health and Nutrition Examination Survey. Analytic and Reporting Guidelines. Hyattsville, MD: US Department of Health and Human Services, CDC; available at http://www.cdc.gov/nchs/data/nhanes/nhanes_03_04/ nhanes_analytic_guidelines_dec_2005.pdf

31. Flores G, Olson L \& Tomany-Korman SC (2005) Racial and ethnic disparities in early childhood health and health care. Pediatrics 115, e183-e193.

32. Rao JNK \& Scott AJ (1981) The analysis of categorical data from complex sample surveys: chi-squared goodness-of-fit and independence in two-way tables. J Am Stat Assoc 76, 221-230.

33. Goldbourt U \& Tanne D (2002) Body height is associated with decreased long-term stroke but not coronary heart disease mortality? Stroke 33, 743-748.
34. Pi-Sunyer FX (1999) Comorbidities of overweight and obesity: current evidence and research issues. Med Sci Sports Exerc 31, Suppl., S602-S608.

35. Nord M, Andrews M \& Winicki J (2002) Frequency and duration of food insecurity and hunger in US households. $J$ Nutr Educ Behav 34, 194-201.

36. Kirkpatrick SI \& Tarasuk V (2008) Food insecurity is associated with nutrient inadequacies among Canadian adults and adolescents. J Nutr 138, 604-612.

37. Silventoinen K, Kaprio J, Koskenvuo M \& Lahelma E (2003) Association between body height and coronary heart disease among Finnish twins and singletons. Int $J$ Epidemiol 32, 78-82.

38. Allebeck P \& Bergh C (1992) Height, body mass index and mortality: do social factors explain the association? Public Health 106, 375-382.

39. Wright ME, Chang SC, Schatzkin A, Albanes D, Kipnis V, Mouw T, Hurwitz P, Hollenbeck A \& Leitzmann MF (2007) Prospective study of adiposity and weight change in relation to prostate cancer incidence and mortality. Cancer 109, 675-684.

40. Stuff JE, Casey PH, Szeto KL, Gossett JM, Robbins JM, Simpson PM, Connell C \& Bogle ML (2004) Household food insecurity is associated with adult health status. J Nutr 134, 2330-2335.

41. Sharkey JR (2003) Risk and presence of food insufficiency are associated with low nutrient intakes and multimorbidity among homebound older women who receive homedelivered meals. J Nutr 133, 3485-3491.

42. El-Bastawissi AY, Peters R, Sasseen K, Bell T \& Manolopoulos R (2007) Effect of the Washington Special Supplemental Nutrition Program for Women, Infants and Children (WIC) on pregnancy outcomes. J Matern Child Health 11, 611-621.

43. Black MM, Cutts DB \& Frank DA (2004) Special Supplemental Nutrition Program for Women, Infants, and Children participation and infants' growth and health: a multisite surveillance study. Pediatrics 114, 169-176.

44. Bray GA \& Bouchard C (1997) Genetics of human obesity: research directions. Obes Res 11, 937-945.

45. Zizza CA, Duffy P \& Gerrior SA (2008) Food insecurity is not associated with lower energy intakes. Obesity 16, 1908-1913.

46. Troisi RJ, Heinold JW, Vokonas PS \& Weiss ST (1991) Cigarette smoking, dietary intake, and physical activity: effects on body fat distribution - the Normative Aging Study. Am J Clin Nutr 53, 1104-1111.

47. Klesges RC, Eck LH, Isbell TR, Fullton W \& Hanson CL (1990) Smoking status: effects on the dietary intake, physical activity, and body fat of adult men. Am J Clin Nutr 51, 784-789.

48. Lissner L, Bengtsson C, Lapidus L \& Bjorkelnd C (1992) Smoking initiation and cessation in relation to body fat distribution based on data from a study of Swedish women. Am J Public Health 82, 273-275.

49. Manson JE, Stampfer MJ, Hennekens $\mathrm{CH}$ \& Willet WC (1987) Body weight and longevity, a reassessment. JAMA 257, 353-358.

50. Armour BS, Pitts MM \& Lee CW (2008) Cigarette smoking and food insecurity among low-income families in the United States, 2001. Am J Health Promot 22, 386-392.

51. Flegal KM (1997) Is an inverted weight-height index a better index of fatness? Obes Res 5, Suppl. 1, 93S.

52. Deurenberg P (1996) Limitations of the bioelectrical impedance method for the assessment of body fat in severe obesity. Am J Clin Nutr 64, Suppl., 449S-452S. 